\title{
MicroRNA Gene Dosage Alterations and Drug Response in Lung Cancer
}

\author{
Katey S. S. Enfield, ${ }^{1}$ Greg L. Stewart, ${ }^{1}$ Larissa A. Pikor, ${ }^{1}$ Carlos E. Alvarez, ${ }^{2}$ Stephen Lam, ${ }^{1}$ \\ Wan L. Lam, ${ }^{1}$ and Raj Chari ${ }^{1}$ \\ ${ }^{1}$ British Columbia Cancer Research Centre, 675 West 10th Avenue, Vancouver, BC, Canada V5Z 1 L3 \\ ${ }^{2}$ Research Institute, Nationwide Children's Hospital, Columbus, OH 43205-2664, USA \\ Correspondence should be addressed to Katey S. S. Enfield, kenfield@bccrc.ca
}

Received 1 November 2010; Accepted 27 January 2011

Academic Editor: E. Felip

Copyright (C) 2011 Katey S. S. Enfield et al. This is an open access article distributed under the Creative Commons Attribution License, which permits unrestricted use, distribution, and reproduction in any medium, provided the original work is properly cited.

\begin{abstract}
Chemotherapy resistance is a key contributor to the dismal prognoses for lung cancer patients. While the majority of studies have focused on sequence mutations and expression changes in protein-coding genes, recent reports have suggested that microRNA (miRNA) expression changes also play an influential role in chemotherapy response. However, the role of genetic alterations at miRNA loci in the context of chemotherapy response has yet to be investigated. In this study, we demonstrate the application of an integrative, multidimensional approach in order to identify miRNAs that are associated with chemotherapeutic resistance and sensitivity utilizing publicly available drug response, miRNA loci copy number, miRNA expression, and mRNA expression data from independent resources. By instigating a logical stepwise strategy, we have identified specific miRNAs that are associated with resistance to several chemotherapeutic agents and provide a proof of principle demonstration of how these various databases may be exploited to derive relevant pharmacogenomic results.
\end{abstract}

\section{Introduction}

Lung cancer is the most common cause of cancer-related deaths worldwide, with a five-year survival rate of less than $15 \%$ [1]. The high incidence of late-stage diagnosis and a lack of efficient therapeutic strategies remain key contributors to the dismal survival statistics. Thus, to improve lung cancer patient outcome, improvement in early detection and a better understanding of the underlying tumor biology that governs response to therapy are necessary. Response to systemic therapy has been shown to be strongly associated with a variety of clinical and molecular features. For example, the chemotherapeutics Avastin and Permetrexed have shown differential response or adverse effects in different histological subtypes of lung cancer [2,3]. Tyrosine kinase inhibitors (TKIs) targeting the epidermal growth factor receptor (EGFR) have shown preferential efficacy in Asian females who typically harbor sequence mutations in EGFR as well as those individuals who harbored EGFR amplifications, EGFR mutations, and the absence of KRAS mutations [4-6].
Very recently, inhibitors to ALK rearrangement also showed significant response in patients who harbor this genetic alteration [7].

In addition to molecular features that can predict sensitivity, there are also examples of features that can predict resistance. In ovarian cancer, resistance to therapy was observed in those individuals who carried amplifications of genes such as P-glycoprotein as well as specific regions in the genome such as $19 \mathrm{q} 12$ and $20 \mathrm{q} 11.22-\mathrm{q} 13.12[8,9]$. With respect to lung cancer, while there are individuals who do respond to TKIs, a large proportion will develop resistance to these therapies by acquiring an additional EGFR mutation (T790M), amplification of the $c-M E T$ oncogene, or hypermethylation of the PTEN locus [10-12]. High levels of ERCC1 mRNA and protein, a key player in nucleotide excision repair, have been associated with resistance to platinum-based chemotherapy [13]. Similarly, low levels of RRM1/2 mRNA and protein were associated with favorable gemcitabine response in NSCLC patients [14]. 
Although alterations in protein-coding genes remain a main focus to elucidate sensitivity or resistance to chemotherapy, deregulation of microRNAs (miRNAs) has recently been shown to play a role in chemotherapy response [15-17]. miRNAs are small noncoding RNAs approximately 18-25 nucleotides in length that negatively regulate gene expression posttranscriptionally $[18,19]$. miRNA biogenesis begins with a long, double-stranded RNA known as a primiRNA, typically hundreds to thousands of nucleotides in length, which is processed into sequentially shorter doublestranded RNA sequences by the endonucleases Drosha and Dicer that are of 70 and 22 nucleotides in size, respectively $[20,21]$. Dissociation of the duplex and incorporation of the mature strand into the RNA-induced silencing complex (RISC) guides RISC to the target mRNA, where the miRNA exhibits its effect [22]. miRNAs bind target transcripts based on sequence similarity-typically in the $3^{\prime}$ UTR of the transcript and sometimes in the $5^{\prime}$ UTR and the coding region-resulting in inhibition of translation or transcript degradation $[18,19,23]$.

The relevance of miRNA deregulation to cancer biology arises because increased expression of certain miRNAs can result in downregulation of tumor suppressor genes, while decreased expression of other miRNAs can lead to increased expression of oncogenes [20,21]. Often located at chromosomal breakpoint regions, fragile sites, and minimal regions of loss of heterozygosity or amplification, miRNA loci are highly susceptible to genomic alterations and subsequently, deregulated expression [24-27]. Aberrant miRNA expression is a common feature of both dysplasia and cancer, and miRNA expression profiles have been associated with prognosis, disease progression, survival, and outcome prediction $[28,29]$. Further, miRNA expression profiles have been found to be superior to global mRNA expression profiles for the accurate definition of cancer types [30,31]. Lung cancer drug response has been associated with the deregulation of several miRNAs. For example, sensitivity of nonsmall cell lung cancer (NSCLC) to cisplatin treatment was linked to upregulation of $m i R-181 a$, while resistance was conferred by upregulation of $m i R-630$ [32]. Sensitivity to another chemotherapeutic agent, Gefitinib, was correlated with loss of $m i R-128 b$ [33]. Several studies have shown that the overexpression of specific miRNAs, such as miR-134 and let-7a, can increase drug sensitivity, demonstrating the therapeutic potential of miRNAs $[34,35]$.

In this study, we sought to determine the role of DNA copy number alterations at miRNA loci in chemotherapy response. As a proof of principle, making use of datasets generated by multiple institutions, encompassing we performed an integrative and comparative DNA dosage and expression alteration analysis of miRNA loci in highly sensitive and resistant lung cancer cell lines for 18 different chemotherapeutics. Using a rigorous, stepwise analysis strategy, we identified four miRNAs which were frequently gained and overexpressed in lung cancer cell lines resistant to one or two of five different chemotherapeutic agents. Subsequent gene expression and gene network analyses for each set of mRNA targets of a given miRNA revealed functions such as DNA replication and repair and cellular assembly and maintenance that were overrepresented in all four sets. These findings demonstrate the feasibility and the value of integrative analysis of multidimensional publicly accessible databases as a strategy for pharmacogenomics discovery.

\section{Material and Methods}

2.1. Drug Response Profiles of Cancer Cell Lines. Drug response $\mathrm{IC}_{50}$ data for 18 different chemotherapeutics across 350 cancer cell lines (See Supplementary Material available online at doi: 10.1155/2011/474632 Supplemental Table 1) was generated as part of the Wellcome Trust Sanger Institute and Massachusetts General Hospital's (MGH) joint Genomics of Drug Sensitivity in Cancer Project. Data was downloaded from the following website: (http://www .sanger.ac.uk/genetics/CGP/translation/compound_sens_data.shtml). Briefly, $\mathrm{IC}_{50}$ is the required concentration of a particular drug to cause in vitro growth to be inhibited by $50 \%$, and thus, a measure of drug effectiveness. A low $\mathrm{IC}_{50}$ indicates that a drug is very effective at inhibiting growth while a high $\mathrm{IC}_{50}$ indicates that a drug is less effective and thus requires a higher dosage to function. Of the 350 cancer cell lines, 73 cell lines were of lung origin.

\subsection{Generation of DNA Copy Number Profiles for Cancer Cell} Lines. Affymetrix SNP 6.0 data for the cancer cell lines were obtained from the Wellcome Trust Sanger Institute CGP Data Archive (http://www.sanger.ac.uk/genetics/CGP/Archive/). Of the 73 lung cancer cell lines with drug response data, 67 of them also had matching SNP array hybridization data (Supplemental Table 2). SNP array data were normalized using default parameters in Partek Genomics Suite (PGS, Partek Inc, St. Louis, MI). Whole genome copy number profiles were visualized using SIGMA ${ }^{2}$ software [36].

\section{3. miRNA and mRNA Expression Data for Cancer Cell} Lines. The current annotation of autosomal miRNAs and their genomic coordinates were obtained from the UCSC Genome Browser (http://www.genome.ucsc.edu/) using the NCBI36/hg18 mapping [37]. miRNA and mRNA expression profiles for lung cancer cell lines were downloaded from the Broad Institute (http://www.broadinstitute.org/cgibin/cancer/datasets.cgi) under the "Sanger Cell Line Project." Affymetrix HG-U133A mRNA expression data were RMAnormalized using the "affy" package in Bioconductor in $R$ [38-40]. Mapping of probes to genes was performed using the Affymetrix NetAffx annotation file (version NA31). Of the 73 lung cancer cell lines with drug response data, 64 had matching miRNA expression while 68 had matching mRNA expression data (Supplemental Table 2).

\subsection{Determination of Predicted miRNA Targets. TargetSpy} (version 1.0) and TargetScan (version 5.1) miRNA target prediction software were used to identify mRNA targets for further analyses [41-44]. For TargetSpy, the "no seed requirement, high sensitivity" set of targets were used, while for TargetScan, the nonconserved miRNA-mRNA targets 
were used. For the miRNAs that were further assessed for target analysis, only miRNA-mRNA target pairs that were present in both databases were assessed for gene expression differences.

2.5. Statistical Analysis. For DNA alteration analysis, copy number profiles of the cancer cell lines were determined against a pooled reference comprised of 72 cytogenetically normal individuals in the HapMap collection. SNP 6.0 data for the HapMap individuals were obtained through Affymetrix. Subsequently, to determine copy number gains and losses, copy number profiles were subjected to segmentation analysis using the "Genomic Segmentation" algorithm in PGS with the following parameters: minimum genomic markers $=20, P$-value threshold for adjacent regions having significantly different means $=1 \times 10^{-6}$, and $P$-value threshold for deviation from normal (diploid) copy number $=1 \times 10^{-6}$. In addition to meeting $P$-value thresholds, a region was deemed gained if the cell line had $>2.3$ copies while a region was deemed lost if the cell line has $<1.7$ copies. For each cell line, the copy number status for individual miRNA loci were determined by mapping the genomic coordinates of the miRNA loci to the identified regions of alteration.

To determine miRNA loci in differentially altered regions of copy number between highly resistant and sensitive cell lines, for each chemotherapeutic, cell lines were ranked based on their $\mathrm{IC}_{50}$ value. The frequency of copy number gain, loss, and retention were compared between the top $1 / 3$ and bottom $1 / 3$ of cancer cell lines using a 3 by 2 Fisher's exact test. A miRNA was deemed significant if the $P$ value from the Fisher's exact test was $\leq .05$.

For miRNA and mRNA expression analysis, similar to the differential copy number analysis, cell lines were ranked based on $\mathrm{IC}_{50}$ for each drug. Subsequently, for each miRNA, the expression in the top and bottom tertiles of cell lines was compared using a nonparametric Mann Whitney $U$ test. A miRNA was deemed significant if the $P$ value from the Mann Whitney $U$ test was $\leq .05$.

Upon identifying which lung cancer cell lines (LCCLs) contained matching DNA copy number and drug response profiles, for each chemotherapeutic, we compared the patterns of copy number alteration between the most sensitive and resistant LCCLs for 636 miRNA loci. Of the resulting differentially altered miRNA identified using the above statistical criteria, we filtered out those miRNAs which were both preferentially gained and lost in either highly resistant or highly sensitive LCCLs. We defined these variably altered miRNAs as those whose differential alteration frequency (DAF) of gain, frequency of gain in highly resistant minus the frequency of gain in highly sensitive, was within $10 \%$ of the DAF of loss, which is the frequency of loss in highly resistant minus the frequency of loss in highly sensitive. In parallel, upon identifying LCCLs with both miRNA expression and drug response profiles, we compared the miRNA expression profiles between the most sensitive and resistant LCCLs for 254 miRNAs using the above-mentioned statistical methods. Although 418 unique miRNAs are represented on the microarray platform, we restricted this analysis to the 254 miRNAs that were expressed in at least 4 LCCLs. Subsequently, for each drug, we identified the miRNAs which were both significantly different at the DNA copy number and expression levels that matched in the same direction that is, if a miRNA had higher copy number in the highly resistant LCCLs as compared to the highly sensitive LCCLs, then the expression would also have to be higher, and vice versa. Next, for each significant miRNA, bioinformatic analysis was performed to identify target mRNAs, and mRNA expression profiles for these genes were compared in a similar manner to that performed in the differential DNA copy number and miRNA expression analyses (using TargetSpy and TargetScan; see above). Restricting to those targets whose mRNA expression profiles negatively correlate with miRNA expression profiles, we performed gene network and function analysis using Ingenuity Pathway Analysis to identify significantly overrepresented functions that were common to all sets of differentially expressed miRNA targets. A flow chart illustrating this strategy is shown in Figure 1.

2.6. Gene Network and Pathway Analysis. For each miRNA, the set of differentially expressed target genes were analyzed using Ingenuity Pathway Analysis (Ingenuity Systems, Redwood City, CA) to determine statistically overrepresented networks and pathways. Briefly, a right tailed Fisher's exact test was employed to calculate a $P$-value for the probability that enrichment of functions within the gene list of interest and the entire list of genes in the human genome is due to chance alone. Only the Molecular and Cellular Functions within the Biological Functions analysis were assessed.

\section{Results}

3.1. Copy Number Alterations of miRNA Loci Correlate with Drug Response in Lung Cancer Cell Lines. Sixty seven lung cancer cell lines with available $\mathrm{IC}_{50}$ data were used to analyze miRNA copy number alterations. For each drug, cell lines were sorted based on $\mathrm{IC}_{50}$ values and the frequencies of DNA copy number gain, loss, and retention were compared between the highest (most resistant, $n=22$ ) and the lowest (most sensitive, $n=22$ ) tertile of cell lines. Of the 636 miRNAs assessed, 307 miRNAs (48.3\%) were significantly different between high and low $\mathrm{IC}_{50}$ for at least one drug, and 20 miRNAs (3.1\%) were different for at least four drugs $(P \leq .05$ Fisher's exact test, Table 1, Supplemental Table 3). In addition, among the 307 miRNAs, $58.4 \%$ were either more frequently gained in high $\mathrm{IC}_{50}$ or more frequently lost in low $\mathrm{IC}_{50}$ while $23.6 \%$ were either more frequently lost in high $\mathrm{IC}_{50}$ or more frequently gained in Iow $\mathrm{IC}_{50}$ lung cancer cell lines. The remaining 41 miRNAs (17.9\%), although significantly different, had less than a $10 \%$ DAF difference between resistant and sensitive lines and were, therefore, deemed variably altered (see methods) and subsequently removed. This brought the total number of miRNAs with significant differences in copy number to 266 (Figure 2). In terms of the drug with the most striking pattern of 
Generate copy number profiles for all 636 currently annotated miRNAs from SNP 6.0 data from Wellcome Trust Sanger Institute CGP Data Archive ( $n=128$ LCCLs)
Obtain $\mathrm{IC}_{50}$ data for the 18 drugs analyzed by the Wellcome Trust Sanger Genomics of Drug Sensitivity in Cancer Project $(n=73$ LCCLs $)$
Obtain miRNA expression profiles for 418 miRNAs from the Broad Institute ( $n=117$ LCCLs)

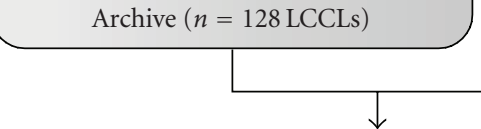
Identify differentially gained and lost miRNA loci between the most sensitive and resistant tertiles for each drug in 67 LCCLs

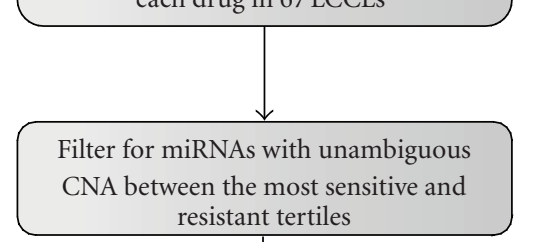

Analyze miRNAs which are expressed in at least 4 LCCLs of 64 LCCLs (254 miRNAs)

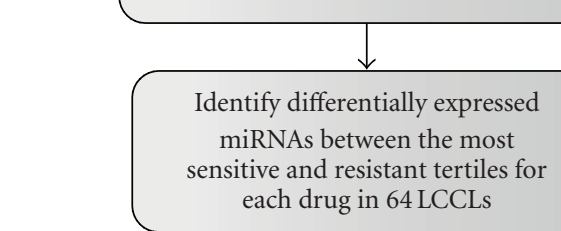

$\downarrow$

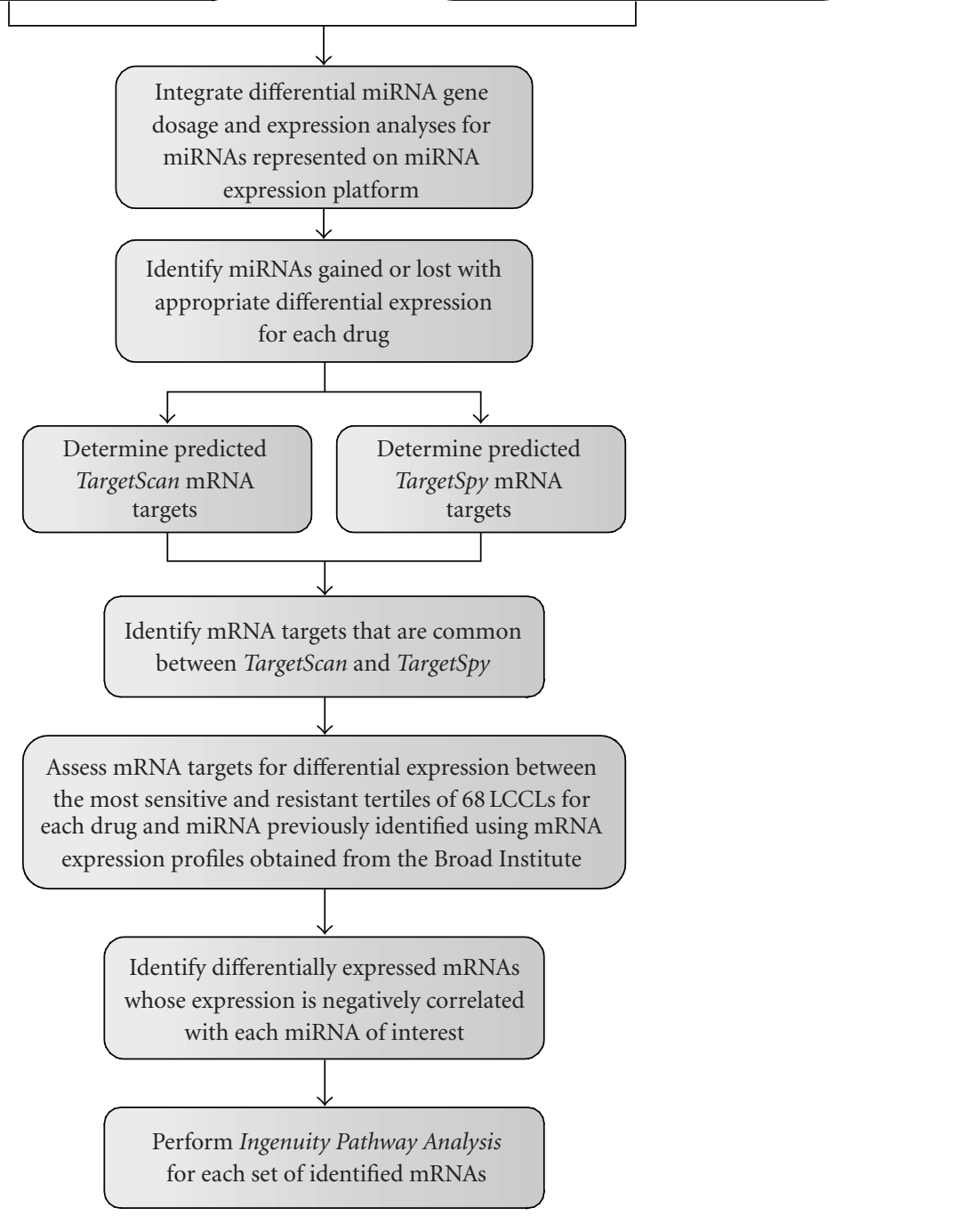

FIGURE 1: The search for drug response-related miRNAs began with data acquisition from several independent databases. Drug response data for lung cancer cell lines (LCCLs) was integrated independently with copy number and expression data, and unique filtering criteria were applied. The integration of all three dimensions applied further filtration criteria, and the remaining miRNAs underwent predicted target analysis. The resulting mRNA target expression was anticorrelated with miRNA expression, and cellular functions of the final mRNA target list were derived by Ingenuity Pathway Analysis. 


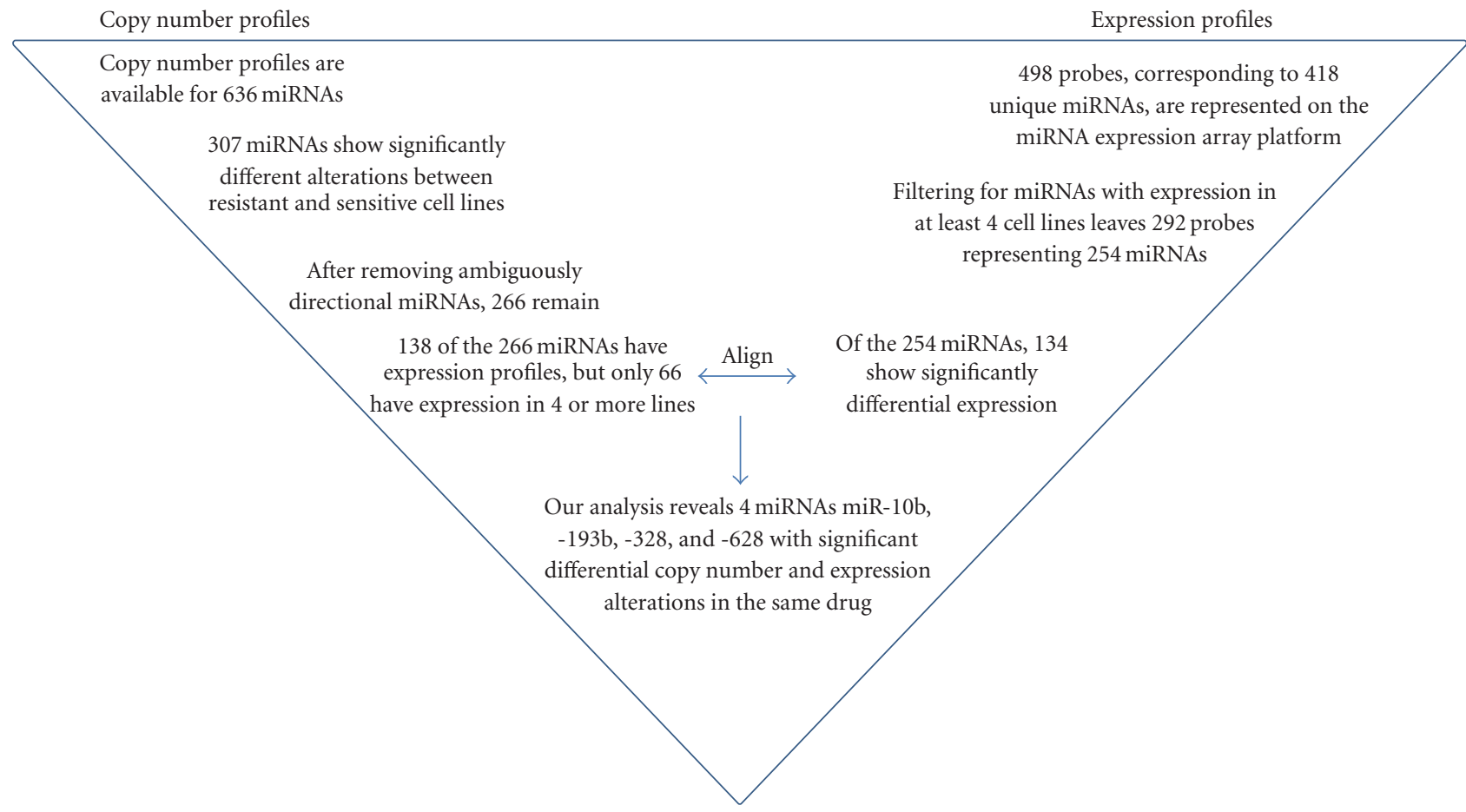

FIGURE 2: Flowchart summarizing the process for the identification of the four miRNAs which correlated significantly with drug response.

differential alteration between high and low $\mathrm{IC}_{50}$ cell lines, TAE684, a small molecule ALK fusion kinase inhibitor, had 66 miRNAs that were significantly different between the most resistant and most sensitive cell lines (Figure 3). Conversely, $\mathrm{miR}-662$ was the most frequently differentiallyaltered miRNA across all of the drugs, appearing significant in 6 of 18 drugs.

3.2. miRNA Expression Levels Correlate with Drug Response in Lung Cancer Cell Lines. miRNA expression was assessed in 64 lung cancer cell lines using a similar method to that applied for identifying copy number alteration differences, comparison of the highest and lowest tertile of cell lines $(n=$ 21) based on $I_{50}$ values for each drug. miRNA expression profiles were available for 498 probes measuring 418 unique miRNAs. However, a number of miRNAs have little to no expression. To account for these cases, miRNAs with expression in less than four cell lines were removed, leaving 292 probes which corresponded to 254 unique miRNAs (Figure 2). One hundred thirty four miRNAs (represented by 146 probes) of the $254(52.8 \%)$ miRNAs with available expression data were significant in at least one drug $(P \leq$ .05 , Mann Whitney $U$ test) (Supplemental Table 4), with 18 miRNAs significant in at least four drugs (Table 2). Of the 134 differentially expressed miRNAs, $40 \%$ had higher expression in high $\mathrm{IC}_{50}$, while $60 \%$ had higher expression in low $\mathrm{IC}_{50}$ lung cancer cell lines. HKI-272 had the most miRNAs [30] that were significantly different at the expression level (Figure 4), and miR-625 was the most frequently differentially expressed miRNA, appearing significant in 7 of 18 drugs.
TABle 1: List of miRNA with most frequent differential copy number alterations.

\begin{tabular}{lc}
\hline miRNA & Significant drugs \\
\hline hsa-mir-662 & 6 (AZ, Erl, Gel, Gö, HKI, MK) \\
hsa-mir-124-2 & 5 (Erl, HKI, Ra, Sor, Sun) \\
hsa-mir-1285-2 & 5 (MG, PF, PH, Ra, Sun) \\
hsa-mir-548h-2 & 5 (Gel, HKI, MK, PD, Sor) \\
hsa-mir-1208 & 4 (Cy, Erl, HKI, Sun) \\
hsa-mir-1225 & 4 (AZ, Gö, MK, Sor) \\
hsa-mir-1228 & 4 (Gel, MK, PF, TAE) \\
hsa-mir-1299 & 4 (AZD, Erl, MK, PH) \\
hsa-mir-147 & 4 (Erl, HKI, MK, TAE) \\
hsa-mir-181a-2 & 4 (Erl, HKI, MK, TAE) \\
hsa-mir-181b-2 & 4 (Erl, HKI, MK, TAE) \\
hsa-mir-1827 & 4 (AZ, Gel, Pac, PF) \\
hsa-mir-1972 & 4 (AZ, Gö, MK, Sor) \\
hsa-mir-492 & $4(\mathrm{Gel}, \mathrm{Im}, \mathrm{Pac}, \mathrm{PF})$ \\
hsa-mir-548c & 4 (Gel, MK, PF, TAE) \\
hsa-mir-548d-1 & 4 (Cy, Gö, HKI, Sun) \\
hsa-mir-548f-2 & 4 (Gö, MG, PF, TAE) \\
hsa-mir-600 & 4 (Erl, HKI, MK, TAE) \\
hsa-mir-601 & 4 (Erl, HKI, MK, TAE) \\
hsa-mir-940 & 4 (AZ, Gö, MK, Sor) \\
\hline
\end{tabular}

3.3. Integrative Analysis of miRNA Gene Dosage and Expression Levels in Lung Cancer Cell Lines. To determine if miRNA dosage modulates expression, we compared the 266 miRNAs 

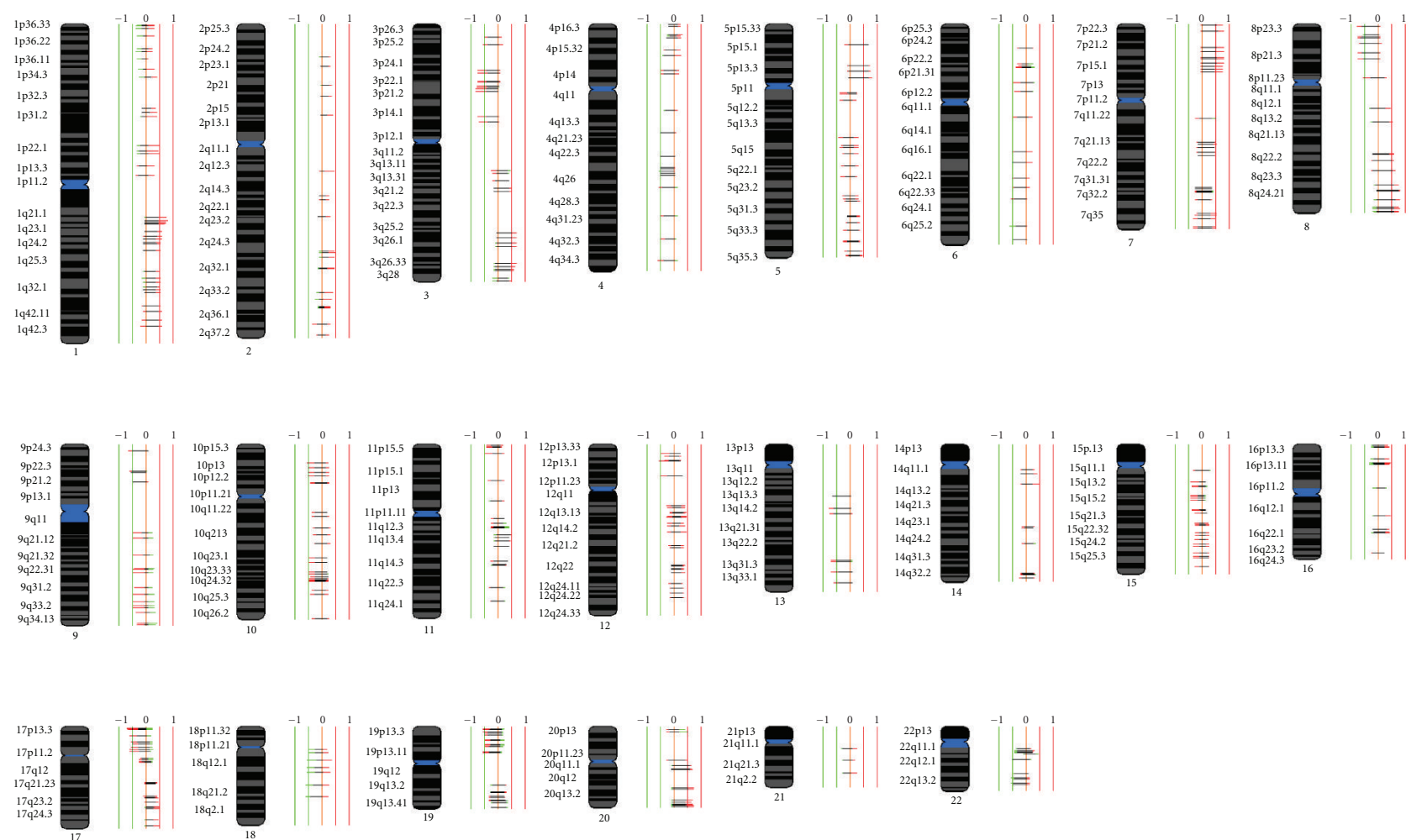

FIGURE 3: Comparison of the frequency of alteration of 636 miRNA loci between highly sensitive and highly resistant lung cancer cell lines (LCCLs) to agent TAE684. Highly sensitive LCCLs were represented by the lowest tertile of IC $_{50}$ while the highly resistant were represented by the highest tertile of $\mathrm{IC}_{50}$. miRNA genomic position information was obtained from the UCSC Genome Browser database [37], and miRNAs on chromosomes X and Y were excluded. Copy number alterations frequencies were plotted using SIGMA ${ }^{2}$ software [36]. Vertical lines denote the frequency of alteration, where 1 or -1 signifies the alteration that occurs in $100 \%$ of samples. Horizontal bars depict miRNAs, with the frequency of copy gains and losses of each miRNA displayed to the right and left of 0 , respectively. miRNAs disrupted in resistant lines are displayed in red, those occurring in sensitive lines are displayed in green, and regions of overlapping frequencies are shown in black.

differentially altered at the copy number level and the 134 miRNAs differentially expressed in at least one of the drugs analyzed. Considering only those miRNAs that were significant at both the copy number and miRNA expression level for the same drug, the intersection of these two lists yielded five miRNAs, miR-10b, $-191,-193 b,-328$, and -628 (Figure 2). Of these five, only expression of four miRNAs, mir-10b, $-193 b,-328$, and -628 matched the direction of their respective copy number alterations. For example, miR628 is more frequently gained in high $\mathrm{IC}_{50}$ lines compared to low $\mathrm{IC}_{50}$ lines treated with agent PF-2341066 and also shows higher expression in high $\mathrm{IC}_{50}$ lines compared to low $\mathrm{IC}_{50}$ lines (Table 3 ), whereas $m i R-191$ is frequently gained in low $\mathrm{IC}_{50}$ lines when treated with TAE684, but shows higher expression in high $\mathrm{IC}_{50}$ lines.

3.4. Gene Expression Analysis of mRNA Targets of miR-10b, $m i R-193 b, m i R-328$, and miR-628. The target prediction software TargetScan and TargetSpy were used to identify putative mRNA targets of miRNAs found to be significantly different at the copy number and miRNA expression levels between high- $\mathrm{IC}_{50}$ and low- $\mathrm{IC}_{50}$ cell lines. For the four miRNAs (miR-10b, miR-328, miR-193b, and miR-628) identified by integrative analyses, only miRNA-mRNA targets present in both databases were used for further analysis. $m i R-10 b$ was identified as having a significant association with response to the proteosome inhibitor MG-132. In total, target prediction analysis found 636 genes that were deemed as putative targets of $m i R-10 b$ (Supplemental Table 5). Comparison of the gene expression profiles between lung cancer cell lines with high and low $\mathrm{IC}_{50}$ for MG-132 revealed 48 of these target genes to be differentially expressed $(P \leq .05$, Mann Whitney $U$ test $)$, with 32 of them showing the expected direction of differential expression (i.e., anticorrelated mRNA expression to miRNA expression) (Table 4).

Interestingly, miR-193b alteration was significantly associated with response to two therapeutics: AZ628 and MK0457 (RAF and aurora kinase inhibitors, resp.). When a similar analysis to $h s a-m i R-10 b$ was performed for $m i R$ $193 b, 518$ genes were identified as putative targets of $m i R$ $193 b$ (Supplemental Table 5). For the analysis of gene expression between highly sensitive and resistant AZ628 cells, 28 of these targets were differentially expressed, with ten of these genes matching the expected direction of differential expression. For MK-0457, 67 of these target genes were differentially expressed with over half (37) matching the expected direction (Table 4).

Alteration of miR-328 was significantly associated with the response to Hsp90 inhibitor Geldanamycin in lung 
TABLE 2: Most frequently different miRNAs at the expression level.

\begin{tabular}{|c|c|}
\hline miRNA & Significant drugs \\
\hline hsa-mir-625 & 7 (Erl, Gö, HKI, MG, Pa, PHA, Ra) \\
\hline hsa-mir-130a & 6 (Erl, Gö, HKI, MG, Pa, Sun) \\
\hline hsa-mir-148a & 6 (AZ, Erl, Gel, Gö, HKI, Pa) \\
\hline hsa-mir-215 & 5 (Gel, Gö, MG, MK, Pa) \\
\hline hsa-mir-518b & 5 (Cy, PF, PHA, Ra, Sun) \\
\hline hsa-mir-100 & 5 (Erl, Gö, HKI, Sun, TAE) \\
\hline hsa-mir-192 & 5 (Gel, Gö, MG, MK, Pa) \\
\hline hsa-mir-375 & 5 (Erl, Gel, Gö, HKI, Pa) \\
\hline hsa-mir-503 & 5 (Cy, Erl, MK, PHA, Ra) \\
\hline hsa-mir-193b & 4 (AZ, MK, PHA, Ra) \\
\hline hsa-mir-521 & 4 (Cy, Erl, Im, PHA) \\
\hline hsa-mir-95 & 4 (Cy, Erl, MG, Sun) \\
\hline hsa-mir-194 & 4 (Gel, Gö, MG, Pa) \\
\hline hsa-mir-205 & 4 (Erl, Gel, Gö, HKI) \\
\hline hsa-mir-222 & 4 (AZ, Erl, Gel, HKI) \\
\hline hsa-mir-27a & 4 (AZD, Erl, Gel, Gö) \\
\hline hsa-mir-377 & 4 (MG, Pa, Sor, Sun) \\
\hline hsa-mir-382 & 4 (AZD, MG, Pa, Sun) \\
\hline
\end{tabular}

cancer cell lines. Of the 437 genes targeted by miR-328, 49 of these genes were significantly differentially expressed between highly resistant and sensitive cell lines, with 31 of the genes matching the expected direction (Supplemental Tables 5 and 4). Finally, for miR-628, whose alteration was significantly associated with the MET inhibitor PF-2341066 response, 392 targets genes were identified with 49 of them being differentially expressed and 22 of those in the appropriate direction (Supplemental Tables 5 and 4).

\section{Discussion}

Chemotherapy response can be influenced by a number of clinicopathological and molecular factors. At the molecular level, while a large focus revolves around the role of activating and inactivating sequence mutations as well as copy number amplifications and deletions in protein coding genes, there has been an increasing emphasis on examining the role of miRNAs and response to chemotherapy. Recent studies have focused on differentially expressed miRNAs in conjunction to resistance and sensitivity to a variety of chemotherapeutics $[32-35,45,46]$. However, the influence of copy number alterations at miRNA loci (or gene dosage) in the context of drug response has not been thoroughly investigated. To this end, we have performed an integrative analysis of genomewide miRNA copy number, miRNA expression, mRNA expression, and drug sensitivity data from 18 different chemotherapeutics on a panel of lung cancer cell lines to identify miRNAs that are significantly different at the copy number and expression levels between the most sensitive and resistant cell lines for a given drug.

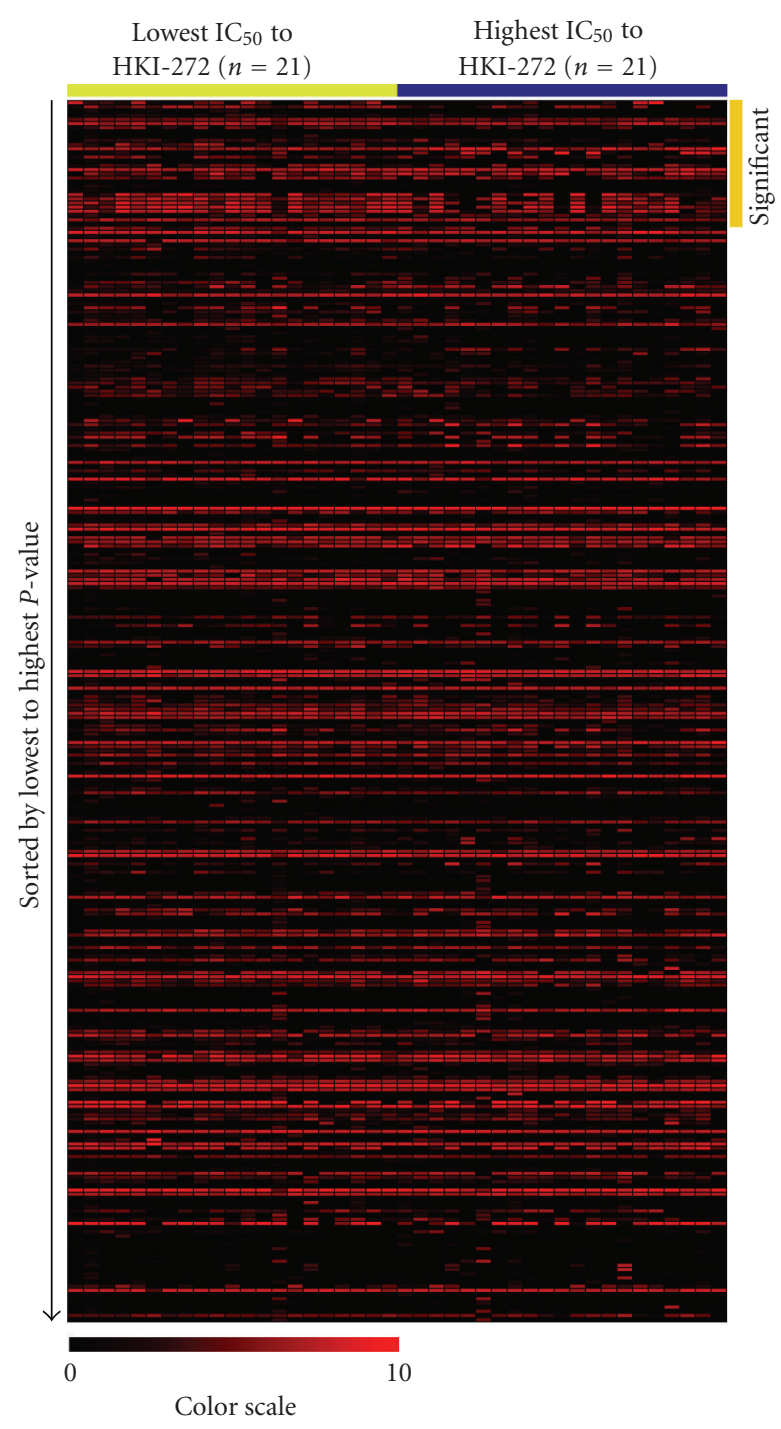

FIgURE 4: Heatmap visualization of the miRNA expression of the 254 miRNAs (represented by 292 unique probes) that passed expression filtering criteria for the 21 most sensitive (yellow bar, low $\mathrm{IC}_{50}$ ) and 21 most resistant (blue bar, high $\mathrm{IC}_{50}$ ) to drug HKI272. In total, 30 miRNAs were found to be significantly differentially expressed between the most sensitive and resistant lung cancer cell lines (LCCLs, orange bar). For this visualization, since a value of 4 represented no expression, all expression values were subtracted by 4 such that baseline expression would be shown as 0 (black).

Upon comparison of the 636 annotated miRNAs throughout the human genome, it was found that 266 of them revealed significant differences in copy number alteration pattern between sensitive and resistant cancer cell lines for at least one drug (Supplemental Table 3). Moreover, of the 266 miRNAs, there were more miRNAs with increased copy number for the highly resistant versus the highly sensitive lung cancer cell lines than vice versa. The miRNA that was found to have a differential pattern of copy number alteration between sensitive and resistant cancer cell lines for the most drugs was miR-662, and, conversely, the drug with most significantly different miRNAs was TAE684. miR-662 is 
TABLE 3: List of miRNAs with significant copy number and expression alterations in the same drug.

\begin{tabular}{lccc}
\hline miRNA & Copy number alteration & Expression alteration & Drug in which significant \\
\hline hsa-mir-10b & Gained, High IC 50 & Overexpressed, High IC $_{50}$ & MG-132 \\
hsa -mir-193b & Gained, High IC 50 & Overexpressed, High IC & AZ628, MK-0457 \\
hsa-mir-328 & Gained, High IC 50 & Overexpressed, High IC & Geldanamycin \\
hsa-mire-628 & Gained, High IC S $_{50}$ & Overexpressed, High IC & PF-2341066 \\
\hline
\end{tabular}

TABLE 4: Differentially expressed mRNA targets for the four identified miRNAs.

\begin{tabular}{|c|c|c|c|c|c|}
\hline miRNA & $10 \mathrm{~b}$ & 328 & $193 b$ & $193 b$ & 628 \\
\hline Drug & $\begin{array}{c}\text { MG-132 (26S } \\
\text { Proteasome inhibitor) }\end{array}$ & $\begin{array}{c}\text { Geldanamycin } \\
\text { (HSP90 inhibitor) }\end{array}$ & $\begin{array}{c}\text { AZ628 (RAF } \\
\text { inhibitor) }\end{array}$ & $\begin{array}{c}\text { MK-0457 (Aurora } \\
\text { kinase inhibitor) }\end{array}$ & $\begin{array}{c}\text { PF-2341066 (MET, } \\
\text { ALK inhibitor) }\end{array}$ \\
\hline \multirow{37}{*}{ Targets } & SMARCC1 & SLC16A1 & PHF15 & EIF2S1 & DCTD \\
\hline & MKRN2 & ANGEL1 & RPP30 & ARIH2 & NUP188 \\
\hline & СМТМб & UBR5 & $R R P 1 B$ & TMEM231 & ELAC1 \\
\hline & CSDE1 & SEMA3C & EIF4B & GABBR1 & DACT1 \\
\hline & MAP4 & MEIS2 & WDR48 & $I K Z F 1$ & CYP7B1 \\
\hline & MYO10 & TRIM32 & PTPN21 & FKTN & RPA4 \\
\hline & NKTR & $G M 2 A$ & CLEC2D & GPATCH8 & GAR1 \\
\hline & $R Y B P$ & EIF2S1 & MRPS16 & $E Z H 1$ & UCKL1 \\
\hline & ZNF532 & $R A C 2$ & NUDT15 & OLFML2A & IL7 \\
\hline & SENP5 & OLFML2A & NECAP2 & PSME3 & $A B C E 1$ \\
\hline & $C B L$ & HIP1 & & $A G T P B P 1$ & CASP3 \\
\hline & WHSC1 & PRKD3 & & NMT2 & WBP4 \\
\hline & FOXJ2 & $V D R$ & & $A D A R B 1$ & KLF9 \\
\hline & $A P O L D 1$ & $Y M E 1 L 1$ & & GREB1 & ACTN2 \\
\hline & PEA15 & TP63 & & SMC5 & GPM6A \\
\hline & $R A D 1$ & TFAP2C & & CCDC28A & LSM12 \\
\hline & CDC6 & CHP2 & & $R N M T$ & PRKCA \\
\hline & UBE2K & STK24 & & C15orf29 & ADAT1 \\
\hline & BNIP2 & GPR126 & & $R R P 1 B$ & PBRM1 \\
\hline & PARD $6 B$ & SERTAD2 & & AGPAT4 & SP2 \\
\hline & FGD6 & DSC2 & & UBA52 & TRAIP \\
\hline & MMP14 & PTGIS & & GOSR1 & MAGOHB \\
\hline & OLFML2A & $R A B 22 A$ & & PRKD3 & \\
\hline & GNL3L & $F B X W 2$ & & SYF2 & \\
\hline & CTDSPL & HS2ST1 & & SSX2IP & \\
\hline & $M M E$ & RPP30 & & $A N K H$ & \\
\hline & PPFIBP1 & SLC16A3 & & ZВТВ39 & \\
\hline & $M 6 P R$ & MAN1A2 & & KBTBD11 & \\
\hline & KPNA6 & TGIF2 & & SEC16A & \\
\hline & RMI1 & CLEC2D & & PHC3 & \\
\hline & $R B M 15 B$ & & & ZNF510 & \\
\hline & SS18L2 & & & $R T F 1$ & \\
\hline & & & & CYLD & \\
\hline & & & & WDR48 & \\
\hline & & & & BTRC & \\
\hline & & & & CCNT2 & \\
\hline & & & & RAB36 & \\
\hline
\end{tabular}


located on chromosomal region 16p13.3 and was found to be more frequently gained in cell lines highly resistant to AZ628, Erlotinib, Geldanamycin, Gö-6976, HKI-272 (Neratinib), and MK-0457. All of these drugs, except for Geldanamycin, which is an antibody that targets HSP90, are kinase inhibitors [47]. While not much is known of miR-662, it was recently shown that it is transiently upregulated in response to high doses of X-ray radiation in human fibroblasts [48]. It should also be noted that $m i R-124-2, m i R-1285-2$, and $m i R-548 h-2$ were significantly altered for five drugs (Table 1). Similar to $m i R-662$, little is known of miR-548h-2. However, miR-124 has been shown to play a tumor suppressive role in cervical cancer, hepatocellular carcinoma, and glioblastoma, while miR-1285 inhibits $\mathrm{p} 53$ and $\mathrm{p} 21$ expression by targeting the $3^{\prime}$ UTR of $p 53$ transcript [49-52].

To identify differentially expressed miRNAs in our dataset, we employed the same approach used to identify differential copy number alterations by assessing the expression of 254 miRNAs in 64 lung cancer cell lines. We identified 134 unique miRNAs significantly different at the expression level between resistant and sensitive lines in at least one drug. Of which, $40 \%$ overexpressed in highly resistant and $60 \%$ overexpressed in highly sensitive lung cancer cell lines. Of these 134 miRNAs, miR-625, about which little is known regarding function, was the most frequently differentially expressed. It was significantly differentially expressed in the analyses of agents Paclitaxel, HKI-272, Gö-6976, Erlotinib, Rapamycin, PHA665752, and MG-132. In terms of the drug comparisons with the highest number of differentially expressed miRNAs, the comparison between LCCLs highly sensitive and resistant to HKI-272, an irreversible tyrosine kinase inhibitor of HER2, revealed 30 differentially expressed miRNAs.

Previous studies of miRNA deregulation with respect to response of some of the drugs used in our analyses have identified a number of miRNAs whose expression correlates with drug sensitivity. For example, underexpression of miR$34 a$ and overexpression of $m i R-125 b, 2-21,-222$, and -923 confer Paclitaxel resistance in prostate cancer [53] and breast cancer [54], respectively, while for hepatocellular carcinomas expression of let-7c [55], miR-122 [56] and miR$193 b$ [57] confer sensitivity to Sorafenib. Notably, Sorafenib is a multikinase inhibitor with highest potency for RAF; this is consistent with our findings that link mir-193b with resistance to the RAF inhibitor AZ628. In addition, underexpression of $m i R-130 a$ and -126 was correlated with resistance to Paclitaxel [58] and Imatinib [59], respectively. From our analyses, we observed miR-130 and -126 to be overexpressed in lung cancer cell lines sensitive to Paclitaxel and Imatinib.

Cancer genomes are characterized by widespread genetic aberrations including high-level amplifications, deletions, DNA methylation, mutations, and chromosomal rearrangements. Within the hundreds of alterations in a cancers genome, only a small subset of these alterations drive tumor initiation and progression and DNA alterations with corresponding expression alterations are more likely to contribute to tumorigenesis $[60,61]$. To identify miRNAs likely implicated in drug resistance, we integrated the 266 miRNAs that were significantly different at the copy number level and the 134 miRNAs that were significantly different at the expression level and subsequently filtered for those miRNAs that were differentially expressed and altered in the same drug. Our analysis identified four miRNAs, $m i R$ $10 b,-193 b,-328$, and -628 , that met these criteria. While the overlap of significant miRNAs in the same drug is minimal, stringent selection criteria such as $P \leq .05$ for both copy number and expression alterations, and limited miRNA expression data, likely contributed to the small number of overlapping miRNAs. Importantly, many of the miRNAs most frequently differentially altered at the copy number level (128 of $266,48.1 \%)$ were not represented on the microarray platform. Moreover, when we factored in our expression criteria of expression in at least four cell lines, the number of miRNAs with expression profiles and significantly different copy number alterations was reduced to 66 . The copy number profiles of these miRNAs suggest they may play an important role in drug resistance, dictating the importance and need to assess these uninvestigated miRNAs at the expression level.

The observation that $m i R-10 b$ is differentially gained and overexpressed in resistant cell lines treated with MG132 is consistent with previous findings (Figures 5(a) and $5(\mathrm{~b}))$. $\mathrm{miR}-10 \mathrm{~b}$ is an oncomir whose overexpression has been identified in a variety of cancers [62-67]. Specifically, overexpression of $m i R-10 b$ has been demonstrated to promote the development of metastatic disease in breast cancer and correlate with clinical breast cancer progression, poor overall survival in gastric cancer, and higher grades of malignant glioma. It was also found to be an effective therapeutic target by using antagomirs to reduce expression of HOXD10, subsequently suppressing breast cancer metastasis [62, 64, $66,68]$. Bioinformatic and gene expression analysis of mRNA targets of miR-10b revealed 32 of 636 target genes that were underexpressed in highly resistant cell lines, which have high expression of miR-10b. Amongst the identified genes was RAD1 (Figure 5(c)). RAD1 is part of a complex of proteins known as the 9-1-1 complex, which functions as a heterotrimeric cell cycle checkpoint [69]. The complex, which functions in DNA repair, is recruited to the site of DNA damage or incomplete replication where it recruits DNA polymerases and DNA repair enzymes. RAD1 has been shown to be important in preventing tumor development in response to DNA damage in mice, whereas deletion of $R A D 1$ greatly increased the susceptibility for skin tumor development [70]. In addition, RAD1 is an important component of nucleotide excision repair (NER) which can have drastic effects on chemotherapy drug response. In drugs that instill double stranded DNA breaks, such as the platinum based treatment Cisplatin, upregulation of NER increases drug resistance while in certain non-DNA damage based chemotherapies, downregulation of NER has been shown to increase resistance $[71,72]$. In NSCLC patients that have low expression of ERCC1, a gene also involved with NER, have decreased survival when compared to patients with high ERCC1 expression [73], and in both murine and human cells, low XPC expression, another gene involved in NER, correlated with resistance to the Doxorubicin derivative, Nemorubicin [72]. Intriguingly, one of the overrepresented 


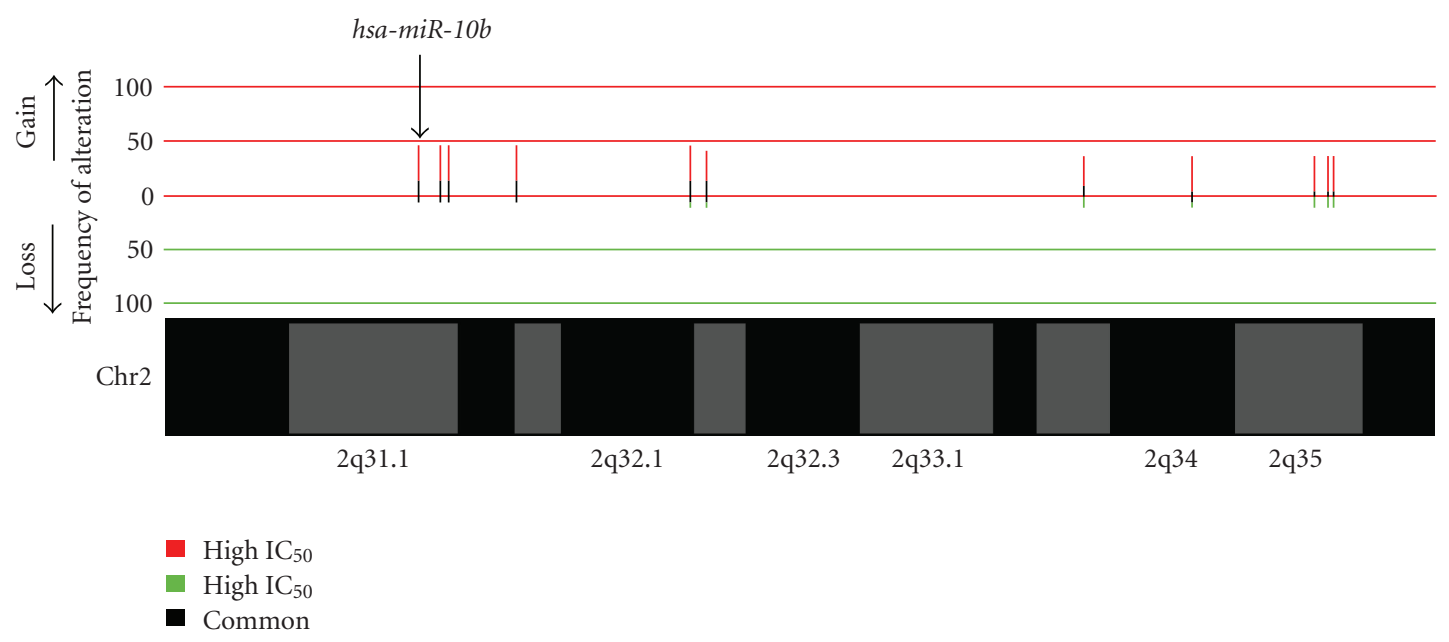

(a)

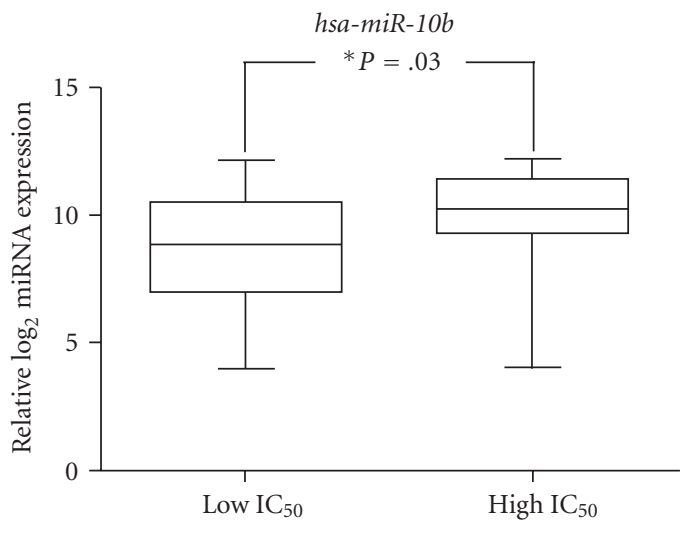

(b)

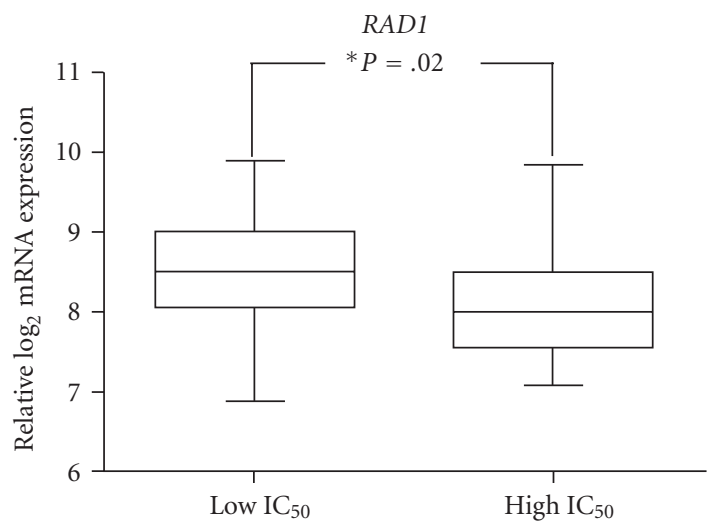

(c)

FIGURE 5: Example of a miRNA showing differentially copy number alteration, differential miRNA expression, and differential target gene expression. (a) Copy number alteration comparison between cell lines which are highly resistant and sensitive to agent MG-132 revealed that the hsa-miR-10b locus, on chromosomal region 2q31.1, is more frequently gained in the highly resistant cell lines $(P<.05$, Fisher's exact test). (b) miRNA expression analysis of miR-10b shows that expression is significantly higher in highly resistant cell lines as compared to sensitive cell lines to MG-132 ( $P=.03$, Mann Whitney $U$ test). (c) mRNA expression analysis of $R A D 1$, a gene identified by bioinformatics prediction analysis as a putative target of miR-10b, shows anticorrelative expression to miR-10b expression. Specifically, decreased expression of RAD1 in highly resistant cell lines to MG-132 relative to highly sensitive lines is observed.

functions identified by Ingenuity Pathway Analysis of the 32 differentially expressed target genes was DNA Replication, Recombination, and Repair (Figure 6).

Expression patterns of $m i R-193 b$ in human cancers, unlike $m i R-10 b$, are largely variable. High expression of $m i R$ $193 b$ is frequently observed in head and neck squamous cell carcinomas and is associated with a high risk of metastatic disease in uveal melanoma $[74,75]$. Conversely, in other cancer types, overexpression of $m i R-193 b$ has elicited increased tumor suppression as well as sensitivity to specific chemotherapeutics $[57,76,77]$. Moreover, conflicting results have also been observed within a given cancer type. In malignant cutaneous melanoma, overexpression of $m i R$ $193 \mathrm{~b}$ predicts disease outcome and is associated with poor survival, while induced overexpression in cell lines repressed proliferation through the downregulation of Cyclin D1 [78, 79]. Subsequent gene expression analysis of target mRNAs of $m i R-193 \mathrm{~b}$ revealed 10 genes that were underexpressed in cell lines highly resistant to AZ628and 37 genes that were underexpressed in cell lines highly resistant to MK0457. One of the target genes that was also differentially expressed was IKAROS family zinc finger 1 (IKZF1). This transcription regulating gene functions through associations with complexes that are both histone deacetylase (HDAC)dependent and HDAC-independent [80]. Previous studies have shown that nonhigh-risk ALL9 patients with IKZF1 deletions show a 12 -fold higher rate of relapse compared to patients without IKZF1 deletions and IKZF1 deletion has also been implicated in tyrosine kinase inhibitor (TKI) resistance and disease progression in patients with chronic phase- (CP-) chronic myeloid leukemia (CML) [81, 82]. Overexpression of an Isoform of IKZF1 lacking a DNA binding domain, IK6, in acute lymphoblastic leukemia (ALL) patients with the Philadelphia chromosome has also been associated with TKI resistance [83]. Interestingly, MK-0457 is a small molecule inhibitor chemotherapy drug that targets 


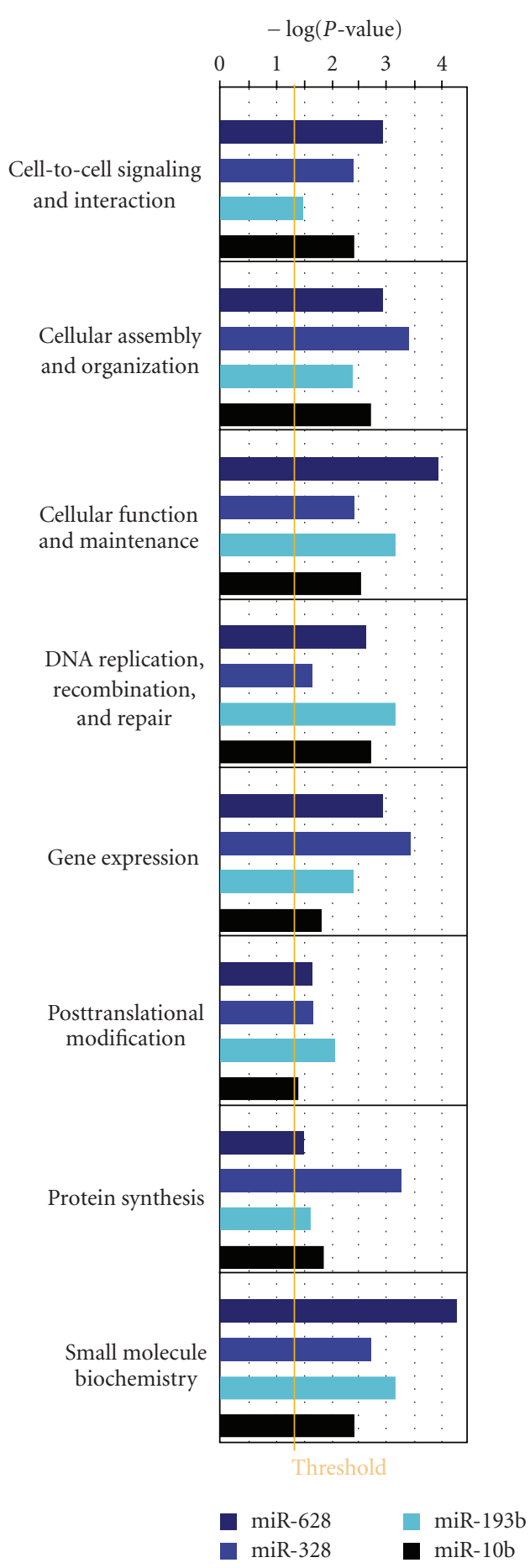

FIGURE 6: Overrepresented cellular and molecular functions that are common to all four sets of differentially expressed target genes. A "Core Analysis Comparison" was performed using Ingenuity Pathway Analysis and within the Biological Functions, only functions within Molecular and Cellular Functions were assessed. In total, eight of these functions were significant in all four sets. The orange threshold line corresponds to a $P$-value of .05.

aurora kinase. Underexpression of $I K Z F 1$ as a result of $m i R$ $193 b$ targeted degradation may increase resistance to MK0457 in a similar mechanism to TKI resistance.
Similar to $m i R-193 b$, evidence supporting the role of $m i R-328$ in cancer is also unclear. In lung adenocarcinoma, $m i R-328$ has been shown to be overexpressed in tumor tissue relative to matched nonmalignant tissue regardless of EGFR or KRAS mutation status [28]. However, in other cancer types, $m i R-328$ underexpression, for example, enables drug resistance through the upregulation of $A B C G 2$ and correlates with cancer progression [84-86]. Our analyses revealed $m i R$ 328 to be gained and overexpressed in lung cancer cell lines resistant to Geldanamycin, an antibody against HSP90. Target and gene expression analysis of $m i R-328$ identified 31 genes underexpressed in cell lines highly resistant to Geldanamycin, with one of the targets being the Vitamin $D$ receptor $(V D R)$. VDR and its downstream components, have been previously shown to have antiproliferative effects in a wide variety of cancer types. The anticancer effects of VDR signaling are mostly mediated through its active metabolite, 1,25-dihydroxyvitamin D (calcitriol), which has been shown to exhibit anti-inflammatory effects as well as the suppression of tumor angiogenesis, invasion, and metastasis $[87,88]$. Expression of $V D R$ has also been shown to be associated with increased survival in breast, colorectal cancer, and cholangiocarcinoma. It has been recently shown that nuclear VDR status may be a prognostic marker of improved survival in patients with NSCLC [88]. Another intriguing finding for $m i R-328$-associated mRNAs is the implication of both $\mathrm{H}(+)$-monocarboxylate cotransporter (MCT) proteins 1 and 4 (SLC16A1/MCT1 and SLC16A3/MCT4). MCT1 and 4 are involved in lactate uptake and $\mathrm{pH}$ balance. Inhibition of MCT1 in tumors can shift aerobic cancer cells from oxidative phosphorylation (lactate metabolism) to glycolysis (glucose), resulting in the death of hypoxic tumor cells due to glucose deprivation [89].

Relatively little has been reported with regard to the role of $m i R-628$. A recent study revealed that $m i R-628$ was expressed in neuroblastomas with favorable prognosis, while those with unfavorable prognosis were devoid of expression, suggesting a tumor suppressive role in this type of cancer [90]. From our analyses, we identified miR-628 to be gained and overexpressed in resistant lung cancer cell lines treated with agent PF-2341066, a MET and ALK kinase inhibitor which has recently shown tremendous efficacy in a subset of lung cancer patients [7]. While the direction of expression contradicts the findings in neuroblastoma, miRNA tissue specificity may play a role in differential expression patterns. Regardless, further analysis of $m i R-628$ is required to better elucidate its role in human cancers. Target and gene expression analysis of miR-628 revealed 22 genes which were underexpressed in cell lines highly resistant to PF-2341066, with one of these differentially expressed being caspase 3 (CASP3). CASP3 is a gene involved in the caspase apoptosis cascade by activating caspases 6, 7, and 9 through cleavage [91]. Moreover, it is also used as a general indicator of cell death and apoptosis. Notably, PF-2341066, which functions as a TKI inhibitor, was found to induce the caspase cell death cascade in vitro through increased levels of CASP3 [92]. Thus, CASP3 downregulation, as a result of miR-628 targeting, may play a significant role in resistance to PF-2341066. 
While all involved in response to different drugs, the targets of these miRNAs share certain biological functions. Figure 6 illustrates the functions in which the targets of all four miRNAs participate at a statistically significant level. Broadly, if roles such as cellular maintenance and DNA repair were compromised, such cell populations could develop tolerance to the accumulation of mutations, some of which could dictate resistance. Participation in small molecule biochemistry has implications in the alteration of how these administered drugs are processed. Cellular organization and cell-to-cell signaling, if altered, could confer a more invasive phenotype, contributing to drug resistance.

\section{Conclusions}

In conclusion, we have demonstrated our method of integrative analysis of multiple dimensions of data including genome-wide miRNA copy number, miRNA expression, mRNA expression, and drug sensitivity data, all available in the public domain, can be a powerful tool to identify miRNAs and genes involved in drug sensitivity. Through these initial analyses, we have identified miRNAs that may have a role in conferring chemoresistance to a number of drugs. Further in vitro and in vivo analyses of the miRNAs and their respective mRNA targets will be necessary to confirm the findings from this study. In addition, given that nearly half of the miRNAs that were differentially altered were not even represented on the miRNA platform analyzed, evaluation of these miRNAs may prove fruitful when new data becomes available. It should also be noted that miRNA target prediction approaches and algorithms are constantly evolving and increasing number of miRNAmRNA interactions being experimentally validated, potentially revealing important target genes that are not currently implicated. Finally, since the MGH/Sanger collaboration aims to generate drug response profiles for a large number of chemotherapeutics in over 1000 cancer cell lines, as more data becomes available, our approach could identify candidate miRNAs that are associated with multiple drugs which have similar mechanisms of action. Moreover, our strategy could also be repeated in a more specific and clinically relevant manner, which could ultimately lead to the identification of prognostic biomarkers and therapeutic indicators for better disease management and patient outcome.

\section{Acknowledgments}

The authors wish to thank Kelsie Thu for assistance in data processing. This work was supported by funds from the Canadian Institutes for Health Research (MOP 86731, MOP 77903), Canadian Cancer Society (CCS20485), and the United States Department of Defense Congressionally Directed Medical Research Program - Lung Cancer Research Program (LC090634P2). C. E. Alvarez was supported by the United States National Institutes of Health (HG004663). Declaration required by the data source: SNP 6.0 cell line data were downloaded from the Wellcome Trust Sanger Institute
CGP Data Archive (http://www.sanger.ac.uk/genetics/CGP/ Archive/). Authors declare that those carried out the original analysis and collection of the data bear no responsibility for the further analysis or interpretation of it by the authors. Contributed equally to this work. K. S. S. Enfield, G. L. Stewart, and L. A. Pikor.

\section{References}

[1] A. Jemal, R. Siegel, J. Xu, and E. Ward, "Cancer statistics, 2010," CA: Cancer Journal for Clinicians, vol. 60, no. 5, pp. 277$300,2010$.

[2] H. Wakelee and C. P. Belani, "Optimizing first-line treatment options for patients with advanced NSCLC," Oncologist, vol. 10, no. 3, pp. 1-10, 2005.

[3] G. Scagliotti, N. Hanna, F. Fossella et al., "The differential efficacy of pemetrexed according to NSCLC histology: a review of two phase III studies," Oncologist, vol. 14, no. 3, pp. 253263, 2009.

[4] M. Fukuoka, S. Yano, G. Giaccone et al., "Multi-institutional randomized phase II trial of gefitinib for previously treated patients with advanced non-small-cell lung cancer," Journal of Clinical Oncology, vol. 21, no. 12, pp. 2237-2246, 2003.

[5] T. S. Mok, Y. L. Wu, S. Thongprasert et al., "Gefitinib or carboplatin-paclitaxel in pulmonary adenocarcinoma," The New England Journal of Medicine, vol. 361, no. 10, pp. 947957, 2009.

[6] M. L. Sos, K. Michel, T. Zander et al., "Predicting drug susceptibility of non-small cell lung cancers based on genetic lesions," Journal of Clinical Investigation, vol. 119, no. 6, pp. 1727-1740, 2009.

[7] E. L. Kwak, Y.-J. Bang, D. R. Camidge et al., "Anaplastic lymphoma kinase inhibition in non-small-cell lung cancer," The New England Journal of Medicine, vol. 363, no. 18, pp. 1693-1703, 2010.

[8] T. P. H. Buys, R. Chari, E. H. L. Lee et al., "Genetic changes in the evolution of multidrug resistance for cultured human ovarian cancer cells," Genes Chromosomes and Cancer, vol. 46, no. 12, pp. 1069-1079, 2007.

[9] D. Etemadmoghadam, A. Defazio, R. Beroukhim et al., "Integrated genome-wide DMA copy number and expression analysis identifies distinct mechanisms of primary chemoresistance in ovarian carcinomas," Clinical Cancer Research, vol. 15, no. 4, pp. 1417-1427, 2009.

[10] S. Kobayashi, T. J. Boggon, T. Dayaram et al., "EGFR mutation and resistance of non-small-cell lung cancer to gefitinib," The New England Journal of Medicine, vol. 352, no. 8, pp. 786-792, 2005.

[11] W. Pao, V. A. Miller, K. A. Politi et al., "Acquired resistance of lung adenocarcinomas to gefitinib or erlotinib is associated with a second mutation in the EGFR kinase domain," PLoS Medicine, vol. 2, no. 3, article e73, 2005.

[12] R. Bianco, I. Shin, C. A. Ritter et al., "Loss of PTEN/MMAC1/ TEP in EGF receptor-expressing tumor cells counteracts the antitumor action of EGFR tyrosine kinase inhibitors," Oncogene, vol. 22, no. 18, pp. 2812-2822, 2003.

[13] K. Kirschner and D. W. Melton, "Multiple roles of the ERCC1XPF endonuclease in DNA repair and resistance to anticancer drugs," Anticancer Research, vol. 30, no. 9, pp. 3223-3232, 2010. 
[14] R. Rosell, E. Felip, M. Taron et al., "Gene expression as a predictive marker of outcome in stage IIB-IIIA-IIIB nonsmall cell lung cancer after induction gemcitabine-based chemotherapy followed by resectional surgery," Clinical Cancer Research, vol. 10, no. 12, part 2, pp. 4215s-4219s, 2004.

[15] M. Ferracin, A. Veronese, and M. Negrini, "Micromarkers: MiRNAs in cancer diagnosis and prognosis," Expert Review of Molecular Diagnostics, vol. 10, no. 3, pp. 297-308, 2010.

[16] M. Garofalo, G. Condorelli, and C. M. Croce, "MicroRNAs in diseases and drug response," Current Opinion in Pharmacology, vol. 8, no. 5, pp. 661-667, 2008.

[17] R. Hummel, D. J. Hussey, and J. Haier, "MicroRNAs: predictors and modifiers of chemo- and radiotherapy in different tumour types," European Journal of Cancer, vol. 46, no. 2, pp. 298-311, 2010.

[18] D. Anglicheau, T. Muthukumar, and M. Suthanthiran, "MicroRNAs: small RNAs with big effects," Transplantation, vol. 90, no. 2, pp. 105-112, 2010.

[19] A. B. Shyu, M. F. Wilkinson, and A. van Hoof, "Messenger RNA regulation: to translate or to degrade," The EMBO Journal, vol. 27, no. 3, pp. 471-481, 2008.

[20] G. A. Calin and C. M. Croce, "MicroRNA signatures in human cancers," Nature Reviews Cancer, vol. 6, no. 11, pp. 857-866, 2006.

[21] R. Garzon, G. A. Calin, and C. M. Croce, "MicroRNAs in cancer," Annual Review of Medicine, vol. 60, pp. 167-179, 2009.

[22] M. V. Iorio and C. M. Croce, "MicroRNAs in cancer: small molecules with a huge impact," Journal of Clinical Oncology, vol. 27, no. 34, pp. 5848-5856, 2009.

[23] R. Mallick, S. Patnaik, and S. Yendamuri, "MicroRNAs and lung cancer: biology and applications in diagnosis and prognosis," Journal of Carcinogenesis, vol. 9, article 8, 2010.

[24] L. Zhang, J. Huang, N. Yang et al., "microRNAs exhibit high frequency genomic alterations in human cancer," Proceedings of the National Academy of Sciences of the United States of America, vol. 103, no. 24, pp. 9136-9141, 2006.

[25] G. A. Calin, C. Sevignani, C. D. Dumitru et al., "Human microRNA genes are frequently located at fragile sites and genomic regions involved in cancers," Proceedings of the National Academy of Sciences of the United States of America, vol. 101, no. 9, pp. 2999-3004, 2004.

[26] D. T. Starczynowski, R. Morin, A. McPherson et al., "Genomewide identification of human microRNAs located in leukemiaassociated genomic alterations," Blood, vol. 117, no. 2, pp. 595607, 2011.

[27] D. T. Starczynowski, F. Kuchenbauer, B. Argiropoulos et al., "Identification of miR-145 and miR-146a as mediators of the 5q-syndrome phenotype," Nature Medicine, vol. 16, no. 1, pp. 49-58, 2010.

[28] S. Dacic, L. Kelly, Y. Shuai, and M. N. Nikiforova, "MiRNA expression profiling of lung adenocarcinomas: correlation with mutational status," Modern Pathology, vol. 23, no. 12, pp. 1577-1582, 2010.

[29] X. M. Wu and H. S. Xiao, "Mirnas modulate the drug response of tumor cells," Science in China, Series C, vol. 52, no. 9, pp. 797-801, 2009.

[30] J. C. Chuang and P. A. Jones, "Epigenetics and microRNAs," Pediatric Research, vol. 61, no. 5, part 2, pp. 24R-29R, 2007.

[31] J. Lu, G. Getz, E. A. Miska et al., "MicroRNA expression profiles classify human cancers," Nature, vol. 435, no. 7043, pp. 834-838, 2005.
[32] L. Galluzzi, E. Morselli, I. Vitale et al., "miR-181a and miR-630 regulate cisplatin-induced cancer cell death," Cancer Research, vol. 70, no. 5, pp. 1793-1803, 2010.

[33] G. J. Weiss, L. T. Bemis, E. Nakajima et al., "EGFR regulation by microRNA in lung cancer: correlation with clinical response and survival to gefitinib and EGFR expression in cell lines," Annals of Oncology, vol. 19, no. 6, pp. 1053-1059, 2008.

[34] W. C. Cho, "MicroRNAs as therapeutic targets for lung cancer," Expert Opinion on Therapeutic Targets, vol. 14, no. 10, pp. 1005-1008, 2010.

[35] J. S. Oh, J. J. Kim, J. Y. Byun, and I. A. Kim, "Lin28-let7 modulates radiosensitivity of human cancer cells with activation of K-Ras," International Journal of Radiation Oncology Biology Physics, vol. 76, no. 1, pp. 5-8, 2010.

[36] R. Chari, B. P. Coe, C. Wedseltoft et al., "SIGMA: a system for the integrative genomic multi-dimensional analysis of cancer genomes, epigenomes, and transcriptomes," BMC Bioinformatics, vol. 9, article 422, 2008.

[37] B. Rhead, D. Karolchik, R. M. Kuhn et al., "The UCSC genome browser database: update 2010," Nucleic Acids Research, vol. 38, no. 1, database issue, pp. D613-D619, 2009.

[38] R. A. Irizarry, B. Hobbs, F. Collin et al., "Exploration, normalization, and summaries of high density oligonucleotide array probe level data," Biostatistics, vol. 4, no. 2, pp. 249-264, 2003.

[39] L. Gautier, L. Cope, B. M. Bolstad, and R. A. Irizarry, "Affyanalysis of Affymetrix GeneChip data at the probe level," Bioinformatics, vol. 20, no. 3, pp. 307-315, 2004.

[40] R. C. Gentleman, V. J. Carey, D. M. Bates et al., "Bioconductor: open software development for computational biology and bioinformatics," Genome Biology, vol. 5, no. 10, p. R80, 2004.

[41] M. Sturm, M. Hackenberg, D. Langenberger, and D. Frishman, "TargetSpy: a supervised machine learning approach for microRNA target prediction," BMC Bioinformatics, vol. 11, article 292, 2010.

[42] B. P. Lewis, C. B. Burge, and D. P. Bartel, "Conserved seed pairing, often flanked by adenosines, indicates that thousands of human genes are microRNA targets," Cell, vol. 120, no. 1, pp. 15-20, 2005.

[43] A. Grimson, K. K. H. Farh, W. K. Johnston, P. Garrett-Engele, L. P. Lim, and D. P. Bartel, "MicroRNA targeting specificity in mammals: determinants beyond seed pairing," Molecular Cell, vol. 27, no. 1, pp. 91-105, 2007.

[44] R. C. Friedman, K. K. H. Farh, C. B. Burge, and D. P. Bartel, "Most mammalian mRNAs are conserved targets of microRNAs," Genome Research, vol. 19, no. 1, pp. 92-105, 2009.

[45] J. Ma, C. Dong, and C. Ji, "MicroRNA and drug resistance," Cancer Gene Therapy, vol. 17, no. 8, pp. 523-531, 2010.

[46] T. Zheng, J. Wang, X. Chen, and L. Liu, "Role of microRNA in anticancer drug resistance," International Journal of Cancer, vol. 126, no. 1, pp. 2-10, 2010.

[47] C. DeBoer, P. A. Meulman, R. J. Wnuk, and D. H. Peterson, "Geldanamycin, a new antibiotic," Journal of Antibiotics, vol. 23, no. 9, pp. 442-447, 1970.

[48] O. C. Maes, J. An, H. Sarojini, H. Wu, and E. Wang, "Changes in microRNA expression patterns in human fibroblasts after low-LET radiation," Journal of Cellular Biochemistry, vol. 105, no. 3, pp. 824-834, 2008.

[49] S. M. Wilting, R. A. A. van Boerdonk, F. E. Henken et al., "Methylation-mediated silencing and tumour suppressive function of hsa-miR-124 in cervical cancer," Molecular Cancer, vol. 9 , p. 167, 2010. 
[50] J. Silber, D. A. Lim, C. Petritsch et al., "miR-124 and miR137 inhibit proliferation of glioblastoma multiforme cells and induce differentiation of brain tumor stem cells," $B M C$ Medicine, vol. 6, article 14, 2008.

[51] M. Furuta, K. I. Kozaki, S. Tanaka, S. Arii, I. Imoto, and J. Inazawa, "miR-124 and miR-203 are epigenetically silenced tumor-suppressive microRNAs in hepatocellular carcinoma," Carcinogenesis, vol. 31, no. 5, pp. 766-776, 2009.

[52] S. Tian, S. Huang, S. Wu, W. Guo, J. Li, and X. He, "MicroRNA-1285 inhibits the expression of p53 by directly targeting its 3' untranslated region," Biochemical and Biophysical Research Communications, vol. 396, no. 2, pp. 435-439, 2010.

[53] K. Kojima, Y. Fujita, Y. Nozawa, T. Deguchi, and M. Ito, "MiR34a attenuates paclitaxel-resistance of hormone-refractory prostate cancer PC3 cells through direct and indirect mechanisms," Prostate, vol. 70, no. 14, pp. 1501-1512, 2010.

[54] M. Zhou, Z. Liu, Y. Zhao et al., "MicroRNA-125b confers the resistance of breast cancer cells to paclitaxel through suppression of pro-apoptotic Bcl-2 antagonist killer 1 (Bak1) expression," Journal of Biological Chemistry, vol. 285, no. 28, pp. 21496-21507, 2010.

[55] S. Shimizu, T. Takehara, H. Hikita et al., "The let-7 family of microRNAs inhibits Bcl-xL expression and potentiates sorafenib-induced apoptosis in human hepatocellular carcinoma," Journal of Hepatology, vol. 52, no. 5, pp. 698-704, 2010.

[56] S. Bai, M. W. Nasser, B. Wang et al., "MicroRNA-122 inhibits tumorigenic properties of hepatocellular carcinoma cells and sensitizes these cells to sorafenib," Journal of Biological Chemistry, vol. 284, no. 46, pp. 32015-32027, 2009.

[57] C. Braconi, N. Valeri, P. Gasparini et al., "Hepatitis C virus proteins modulate microRNA expression and chemosensitivity in malignant hepatocytes," Clinical Cancer Research, vol. 16, no. 3, pp. 957-966, 2010.

[58] A. Sorrentino, C. G. Liu, A. Addario, C. Peschle, G. Scambia, and C. Ferlini, "Role of microRNAs in drug-resistant ovarian cancer cells," Gynecologic Oncology, vol. 111, no. 3, pp. 478486, 2008.

[59] E. San José-Enériz, J. Román-Gómez, A. Jiménez-Velasco et al., "MicroRNA expression profiling in Imatinib-resistant Chronic Myeloid Leukemia patients without clinically significant ABL1-mutations," Molecular Cancer, vol. 8, article 1476, p. $69,2009$.

[60] B. P. Coe, R. Chari, W. W. Lockwood, and W. L. Lam, "Evolving strategies for global gene expression analysis of cancer," Journal of Cellular Physiology, vol. 217, no. 3, pp. 590597, 2008.

[61] B. Luo, W. C. Hiu, A. Subramanian et al., "Highly parallel identification of essential genes in cancer cells," Proceedings of the National Academy of Sciences of the United States of America, vol. 105, no. 51, pp. 20380-20385, 2008.

[62] L. Ma, J. Teruya-Feldstein, and R. A. Weinberg, "Tumour invasion and metastasis initiated by microRNA-10b in breast cancer," Nature, vol. 449, no. 7163, pp. 682-688, 2007.

[63] D. M. Jukic, U. N. M. Rao, L. Kelly et al., "Microrna profiling analysis of differences between the melanoma of young adults and older adults," Journal of Translational Medicine, vol. 8, article 27, 2010.

[64] T. Sasayama, M. Nishihara, T. Kondoh, K. Hosoda, and E. Kohmura, "MicroRNA-10b is overexpressed in malignant glioma and associated with tumor invasive factors, UPAR and RhoC," International Journal of Cancer, vol. 125, no. 6, pp. 1407-1413, 2009.
[65] N. Dahiya, C. A. Sherman-Baust, T. L. Wang et al., "MicroRNA expression and identification of putative miRNA targets in ovarian cancer," PLoS One, vol. 3, no. 6, Article ID e2436, 2008.

[66] X. Li, Y. Zhang, Y. Zhang, J. Ding, K. Wu, and D. Fan, "Survival prediction of gastric cancer by a seven-microRNA signature," Gut, vol. 59, no. 5, pp. 579-585, 2010.

[67] R. L. Prueitt, M. Yi, R. S. Hudson et al., "Expression of microRNAs and protein-coding genes associated with perineural invasion in prostate cancer," Prostate, vol. 68, no. 11, pp. 1152-1164, 2008.

[68] L. Ma, F. Reinhardt, E. Pan et al., "Therapeutic silencing of miR-10b inhibits metastasis in a mouse mammary tumor model," Nature Biotechnology, vol. 28, no. 4, pp. 341-347, 2010.

[69] H. Bai, A. Madabushi, X. Guan, and A. L. Lu, "Interaction between human mismatch repair recognition proteins and checkpoint sensor Rad9-Rad1-Hus1," DNA Repair, vol. 9, no. 5, pp. 478-487, 2010.

[70] L. Han, Z. Hu, Y. Liu et al., "Mouse Rad1 deletion enhances susceptibility for skin tumor development," Molecular Cancer, vol. 9, article 67, 2010.

[71] K. A. Olaussen, A. Dunant, P. Fouret et al., "DNA repair by ERCC1 in non-small-cell lung cancer and cisplatinbased adjuvant chemotherapy," The New England Journal of Medicine, vol. 355, no. 10, pp. 983-991, 2006.

[72] M. A. Sabatino, M. Marabese, M. Ganzinelli, E. Caiola, C. Geroni, and M. Broggini, "Down-regulation of the nucleotide excision repair gene XPG as a new mechanism of drug resistance in human and murine cancer cells," Molecular Cancer, vol. 9, article 259, 2010.

[73] Z. Ding, J. Zhang, and J. Shao, "ERCC1 expression as a predictor of survival after operation in stage I non-small cell lung cancer patients," Zhongguo Fei Ai Za Zhi, vol. 13, no. 5, pp. 522-525, 2010.

[74] M. Avissar, B. C. Christensen, K. T. Kelsey, and C. J. Marsit, "MicroRNA expression ratio is predictive of head and neck squamous cell carcinoma," Clinical Cancer Research, vol. 15, no. 8, pp. 2850-2855, 2009.

[75] L. A. Worley, M. D. Long, M. D. Onken, and J. W. Harbour, "Micro-RNAs associated with metastasis in uveal melanoma identified by multiplexed microarray profiling," Melanoma Research, vol. 18, no. 3, pp. 184-190, 2008.

[76] X. F. Li, P. J. Yan, and Z. M. Shao, "Downregulation of miR-193b contributes to enhance urokinase-type plasminogen activator ( $\mathrm{UPA}$ ) expression and tumor progression and invasion in human breast cancer," Oncogene, vol. 28 , no. 44 , pp. 3937-3948, 2009.

[77] H. E. Rauhala, S. E. Jalava, J. Isotalo et al., "miR-193b is an epigenetically regulated putative tumor suppressor in prostate cancer," International Journal of Cancer, vol. 127, no. 6, pp. 1363-1372, 2010.

[78] S. Caramuta, S. Egyházi, M. Rodolfo et al., "MicroRNA expression profiles associated with mutational status and survival in malignant melanoma," Journal of Investigative Dermatology, vol. 130, no. 8, pp. 2062-2070, 2010.

[79] J. Chen, H. E. Feilotter, G. C. Paré et al., "MicroRNA$193 \mathrm{~b}$ represses cell proliferation and regulates cyclin D1 in melanoma," American Journal of Pathology, vol. 176, no. 5, pp. 2520-2529, 2010.

[80] J. Kim, S. Sif, B. Jones et al., "Ikaros DNA-binding proteins direct formation of chromatin remodeling complexes in lymphocytes," Immunity, vol. 10, no. 3, pp. 345-355, 1999. 
[81] R. P. Kuiper, E. Waanders, V. H. J. van der Velden et al., "IKZF1 deletions predict relapse in uniformly treated pediatric precursor B-ALL," Leukemia, vol. 24, no. 7, pp. 1258-1264, 2010.

[82] S. Joha, V. Dauphin, F. Leprêtre et al., "Genomic characterization of Imatinib resistance in $\mathrm{CD} 34^{+}$cell populations from chronic myeloid leukaemia patients," Leukemia Research. In press.

[83] I. Lacobucci, A. Lonetti, F. Messa et al., "Expression of spliced oncogenic Ikaros isoforms in Philadelphia-positive acute lymphoblastic leukemia patients treated with tyrosine kinase inhibitors: implications for a new mechanism of resistance," Blood, vol. 112, no. 9, pp. 3847-3855, 2008.

[84] W.-Q. Li, Y.-M. Li, B.-B. Tao et al., "Downregulation of ABCG2 expression in glioblastoma cancer stem cells with miRNA-328 may decrease their chemoresistance," Case Reports and Clinical Practice Review, vol. 16, no. 10, pp. HY27HY30, 2010.

[85] B. Malzkorn, M. Wolter, F. Liesenberg et al., "Identification and functional characterization of microRNAs involved in the malignant progression of gliomas," Brain Pathology, vol. 20, no. 3, pp. 539-550, 2010.

[86] Y. Z. Pan, M. E. Morris, and A. M. Yu, "MicroRNA-328 negatively regulates the expression of breast cancer resistance protein (BCRP/ABCG2) in human cancer cells," Molecular Pharmacology, vol. 75, no. 6, pp. 1374-1379, 2009.

[87] A. V. Krishnan and D. Feldman, "Mechanisms of the anticancer and anti-inflammatory actions of vitamin D," Annual Review of Pharmacology and Toxicology, vol. 51, pp. 311-336, 2011.

[88] M. Srinivasan, A. V. Parwani, P. A. Hershberger, D. E. Lenzner, and J. L. Weissfeld, "Nuclear vitamin D receptor expression is associated with improved survival in non-small cell lung cancer," Journal of Steroid Biochemistry and Molecular Biology, vol. 123, no. 1-2, pp. 30-36, 2011.

[89] P. Sonveaux, F. Végran, T. Schroeder et al., "Targeting lactatefueled respiration selectively kills hypoxic tumor cells in mice," Journal of Clinical Investigation, vol. 118, no. 12, pp. 39303942, 2008.

[90] J. H. Schulte, T. Marschall, M. Martin et al., "Deep sequencing reveals differential expression of microRNAs in favorable versus unfavorable neuroblastoma," Nucleic Acids Research, vol. 38, no. 17, pp. 5919-5928, 2010.

[91] D. W. Nicholson, A. Ali, N. A. Thornberry et al., "Identification and inhibition of the ICE/CED-3 protease necessary for mammalian apoptosis," Nature, vol. 376, no. 6535, pp. 37-43, 1995.

[92] H. Y. Zou, Q. Li, J. H. Lee et al., "An orally available small-molecule inhibitor of c-Met, PF-2341066, exhibits cytoreductive antitumor efficacy through antiproliferative and antiangiogenic mechanisms," Cancer Research, vol. 67, no. 9, pp. 4408-4417, 2007. 


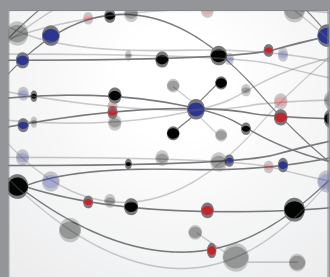

The Scientific World Journal
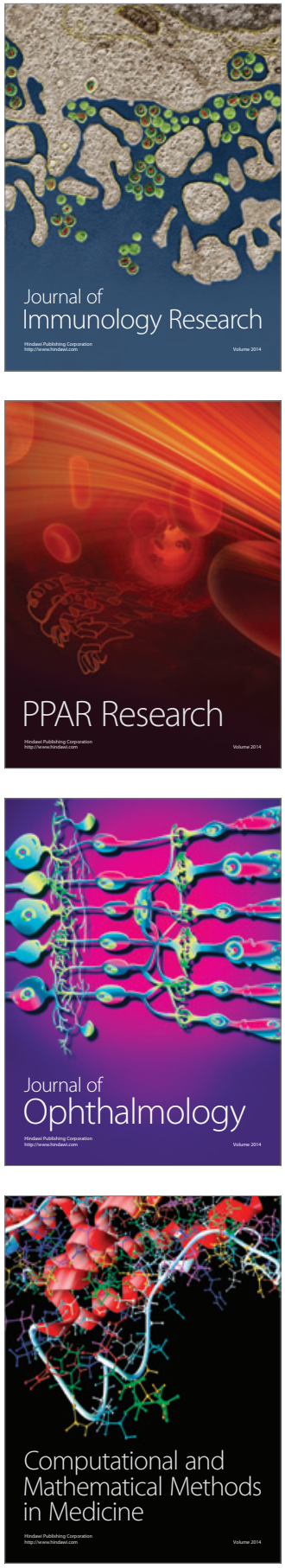

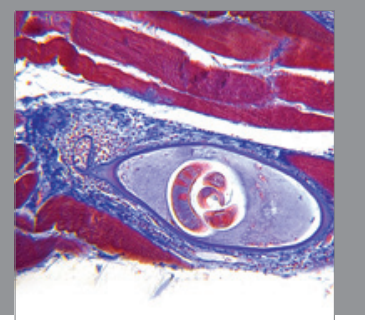

Gastroenterology

Research and Practice
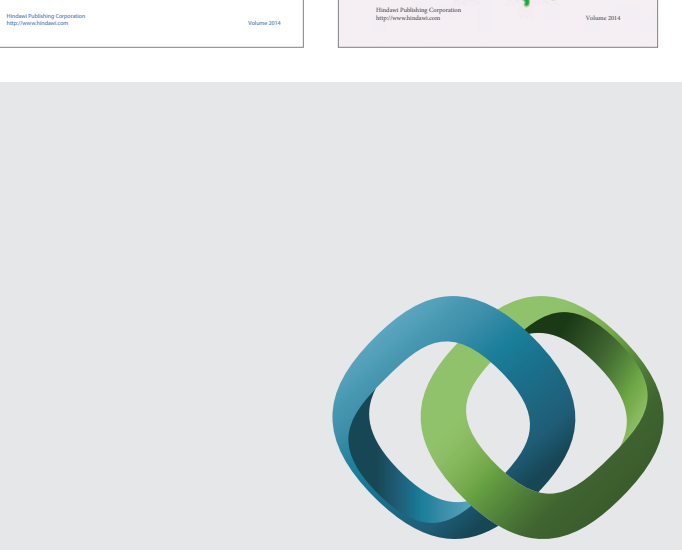

\section{Hindawi}

Submit your manuscripts at

http://www.hindawi.com
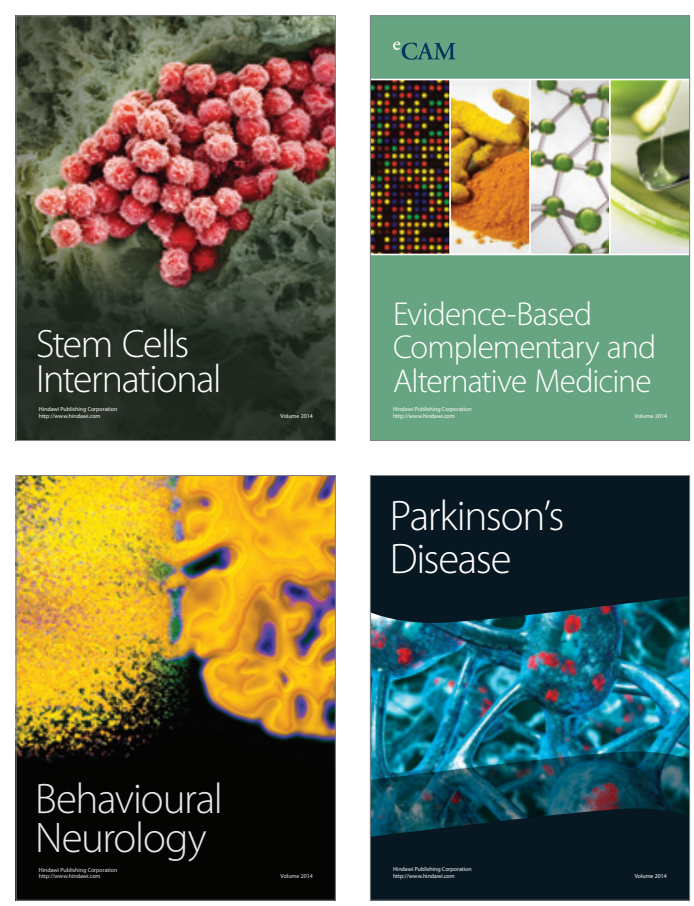

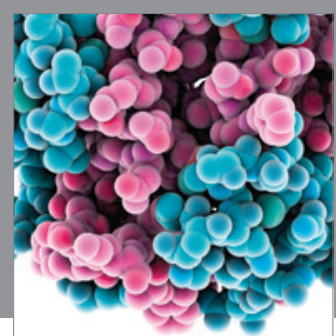

Journal of
Diabetes Research

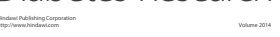

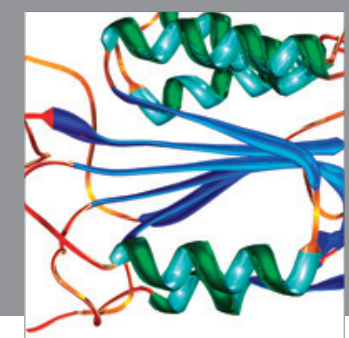

Disease Markers
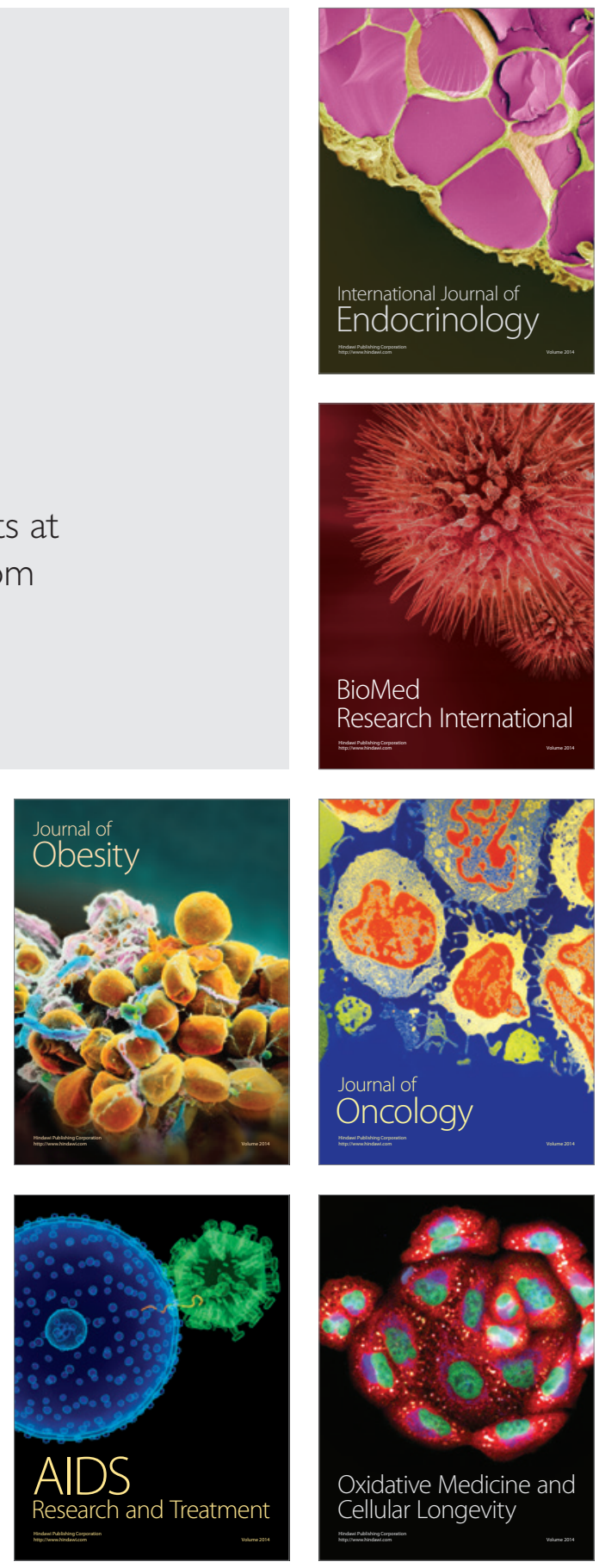